\title{
Этническая культура на глобальной орбите: феномен пространственного развития тувинской народной музыки"
}

\author{
Ольга В. Долженкова \\ Институт философии и права Сибирского отделения Российской академии наук, \\ Российская Федерация
}

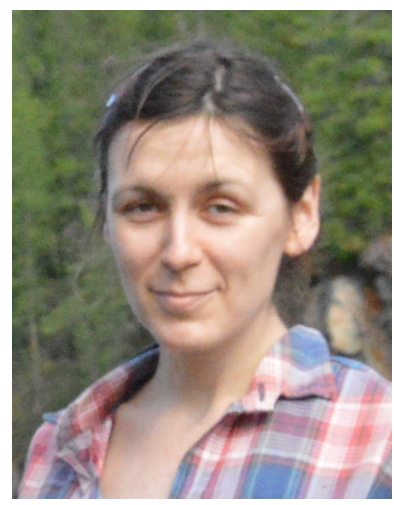

На примере тувинской народной музыки в статье рассматриваются особенности пространственного распространения этнической культуры в современном мире вплоть до глобального уровня. Выявляются значимость содержания локальной, этнической культуры для культуры глобальной (западной), и основа подобной значимости - родовые потребности человека. Реализация данных потребностей в рамках глобальной западной культуры затруднена, поскольку, согласно доминирующей в данном типе культуры системе ценностей, приоритет отдается удовлетворению других групп потребностей.

В статье показывается, что этнокультура обладает способностью реализовать подобные потребности, поскольку включает в себя значимые для обеспечения человеческого существования цеенности, находящиеся на периферии системы цеенностных ориентаций глобальной западной цивилизации. Этническая культура в данном случае выполняет коммуникативную функцию соотнесения с потребностями индивида.

Современная тувинская народная музыка демонстрирует значимость сохранения этнического своеобразия культуры при её одновременной адаптации к тезаурусу представителя западной культуры для обеспечения возможности осуществления подобной коммуникации. Такой баланс нашел выражение в новой эстетике тувинской музыки, спецциика которой заключается в выделении ключевых параметров её звучания - ориентация на тембр, звукоподражание и «тембровый парадокс» - и их переработке в неотрадицию, позволяющую актуализировать такие особенности родовых потребностей индивида, как необходимость в коллективном способе жизни, долговременной перспективе ориентации деятельности и взаимодействии с естественной средой обитания.

Ключевые слова: этническая культура; пространственное развитие; тувинская музыка; тувинская народная музыка; world тиsic; Тува; тувинцы; горловое пение; хоомей; Хун-Хурту

־Работа выполнена по программам фундаментальных научных исследований, определяемых Президиумом РАН.

\section{Для цитирования:}

Долженкова О. В. Этническая культура на глобальной орбите: феномен пространственного развития тувинской народной музыки [Электронный ресурс] // Новые исследования Тувы. 2019, № 3. URL: https://nit.tuva.asia/nit/ article/view/864 (дата обращения: дд.мм.гг.). DOI: 10.25178/nit.2019.3.5

Долженкова Ольга Викторовна - аспирант отдела социальных и правовых исследований Института философии и права Сибирского отделения Российской академии наук. Адрес: 630090, Россия, г. Новосибирск, ул. Николаева, д. 8. Тел.: +7 (383) 330-09-75. Эл. адрес: corpusdva@yandex.ru. Научный руководитель - д-р филос. н., проф. Ю. В. Попков. ORCID ID: 0000-0003-3468-1118

Dolzhenkova Olga Viktorovna, Post-graduate student, Department of Social and Legal Studies, Institute of Philosophy and Law, Siberian Branch of the Russian Academy of Sciences. Postal address: 8, Nikolaeva St., 630090 Novosibirsk, Russian Federation. Tel: +7 (383) 330-09-75. E-mail: corpusdva@yandex.ru. Research advisor - Doctor of Philosophy, Professor Yu. V. Popkov. 


\title{
Ethnic culture in the global orbit: the phenomenon of spatial development of Tuvan folk music
}

\author{
Olga V. Dolzhenkova \\ Institute of Philosophy and Law, Siberian Branch of the Russian Academy of Science, \\ Russian Federation
}

\begin{abstract}
Making use of Tuvan folk music as a case study, the article discusses the features of spatial distribution of ethnic culture in the modern world up to the global level. The author investigates the importance of the content of local ethnic culture for the global (Western) culture, and the basis of such importance is found in ancestral human needs. Within the frame of the global culture, meeting these needs looks difficult since the dominant values system in global culture prioritizes a different group of human needs.

The paper shows how the ethnic culture is capable to meet ancestral needs, since it includes the values, crucial for human existence but located on the periphery of the global (Western) values system. In this case, the ethnic culture performs a communicative function of correlating them with those of an individual.

Modern Tuvan folk music demonstrates the importance of preserving the ethnic identity of culture while adapting it to the thesaurus of the representative of Western culture to ensure the possibility of such communication. Such balance is reflected in the new esthetics of the Tuvan folk music, which is based on amplifying its traditional key sound parameters - a focus on the timbre, onomatopoeia and the 'paradox of timbre'. All of these are converted into neotradition, which re-actualizes such ancestral needs as commitment to a communal type of life, focus on long-term action and on interaction with nature.
\end{abstract}

Keywords: ethnic culture; spatial development; Tuvan music; Tuvan folk music; world music; Tuva; Tuvans; xöömei; throatsinging; Huun-Huur-Tu

"The article was written under the aegis of programs of fundamental research established by the Presidium of the Russian Academy of Sciences.

\section{For citation:}

Dolzhenkova O. V. Ethnic culture in the global orbit: the phenomenon of spatial development of Tuvan folk music. The New Research of Tuva. 2019, no. 3 [online] Available at: https://nit.tuva.asia/nit/article/view/864 (access date ...). DOI: 10.25178/nit.2019.3.5

\section{Введение}

Понятие этнической культуры охватывает сферу явлений материальной и духовной культуры, которая воспринимается как характерная для определенного этноса (Арутюнов, 1989: 166). С переходом от традиционного общества к современному, этническая культура испытывает определенные изменения. Происходит сужение ареала ее присутствия и преимущественное перемещение в духовную сферу (Монгуш, Зайцева, Бакшеев, 2014: Электронный ресурс). Однако, несмотря на указанные процессы, элементы этнической культуры продолжают воспроизводиться в современном мире.

Как представляется, современное развитие этнической культуры концептуально может быть выражено с помощью понятий «глокализация» и «интернационализация». Согласно первому, существуют два взаимодополняющих и взаимопроникающих направления развития общества: гомогенизация и гетерогенизация (Robertson, 1995: 40), согласно второму, глобализация и этническая фрагментация могут рассматриваться как продукты интернационализации (Попков, 2000: 3; Попков, 2012: 1067-1068). Соответственно, можно выделить различные способы, с помощью которых глобальная унифицирующая тенденция развития и этнические феномены как проявление «локального» взаимодействуют между собой. Так, на локальном уровне может происходить усвоение определенных свойств глобального. В качестве подобного усвоения можно рассматривать развитие локального, этнического пространства при помощи брендинга (Культура и пространство ..., 2012). Другим проявлением локального в ответ на распространение глобального является возрождение местных культурных форм (Бергер, 2004: 18-20), каковым является, например, возрождение интереса к бретонской культуре, которое началось в период урбанизации Бретани (Любарт, 2013: 329). 
В качестве второго направления взаимодействия глобального и локального можно рассматривать распространение определенных элементов этнической культуры за пределами свойственного ей региона. Это происходит в том числе потому, что на них существует определенный спрос. Как отмечал еще в 1970-х гг. С. А. Арутюнов, общемировая культура в своем развитии постоянно черпает новые элементы из местных традиционных культур (Арутюнов, 1979: 37). На современном этапе подобная форма развития этнической культуры также может рассматриваться как ответ на глобализацию и происходить в виде так называемых альтернативных моделей глобализации (Бергер, 2004: 18-20). Таковыми являются концепции буддистской или исламской экономики, гандизм ${ }^{1}$, отражающие такие культурные ценности, как ориентация на самосовершенствование, гармония общества и природы и самоограничение в потреблении. Они соответствуют императивам постиндустриального развития (Зарубина, 1998: 222-223, 234-235).

Ещё одной формой проявления взаимодействия глобального и локального является уже отмеченное широкое распространение отдельных элементов конкретной этнической культуры. Характерным примером последнего является возникновение в 1980-х гг. такого явления, как world music, которое, с одной стороны, акцентирует внимание на значении локального в глобальных потоках, а с другой стороны, выводит локальное на глобальный уровень (Connell, Gibson, 2004: 354). Подобное, выходящее вплоть до глобального масштаба за пределы свойственного определенной этнической культуре региона, распространение элементов этнической культуры может рассматриваться как глобальный аспект пространственного развития этнической культуры.

Факт пространственного развития этнической культуры в современном мире позволяет говорить о том, что подобное развитие связано не только с мобильным характером современной глобальной культуры, в которую включается культура этническая, но и со свойствами самой этнокультуры. В данном контексте можно предположить, что этническая культура обладает определенной универсальной понятностью и значимостью, поэтому она не только разъединяет людей разной этнической принадлежности, но и объединяет их, невзирая на этнические различия.

Поскольку, как отмечалось, этническая культура с переходом от традиционного к современному обществу уходит из бытовой и хозяйственной сфер в духовную сферу, в которой также начинает занимать лишь определенную нишу, то этнокультура, в сравнении с культурой массовой, перестает быть непосредственно доступной индивиду. Обращение к этнической культуре на современном этапе требует от индивида определенных поисковых усилий, активности. Подобная активность может рассматриваться как результат переживания индивидом на субъективном уровне необходимости в контакте с этнической культурой. Понятием, которое объединяет в себе перечисленные компоненты: субъективно переживаемую необходимость и активность, является потребность (Ильин, 2002: 33, 21). Поэтому можно говорить о том, что содержащийся в этнической культуре универсальный контент затрагивает определенные потребности индивида.

Соответственно, в качестве фактора пространственного развития этнической культуры в современном мире можно рассматривать определенные потребности индивида, реализации которых отвечает, с одной стороны, процесс глобального развития современной культуры, а с другой стороны, содержание этнической культуры. С учетом фиксации данной проблемы в статье ставится задача определить, какими потребностями индивида и почему обусловлено пространственное развитие этнической культуры, и какова роль этнической специфики культуры в данном процессе.

\footnotetext{
${ }^{1}$ Концепция «исламской экономики» была сформулирована во второй половине XX в. Сам термин утвердился в $1970-е$ гг. Существует как в теоретической форме, так и в виде частичной реализации на практике. В практической форме особенности исламской экономики более всего проявляются в финансовой сфере, где основную её цель составляет поиск альтернативы процентному финансированию (Беккин, 2012: 100). Согласно используемым в исламской экономике методам финансирования, норма прибыли, в отличие от процентной ставки, представляет собой более эффективный и рациональный механизм распределения ресурсов (Беккин, 2010: 64-65). Концепция «буддистской экономики» была разработана в теоретическом виде австрийским исследователем Е. Шумахером. Согласно данной концепции, в основе буддистской экономики лежит производство на основе местных ресурсов и для местного потребления, а также приоритет духовных ценностей над материальными (Старостин: 1984: 161). Появлению концепции способствовал рост участия буддистской общины в хозяйственной жизни и модернизации стран Азии (Сравнительное изучение цивилизаций, 1998: 432-433). Содержание концепции роднит её с идеями гандизма, движения, основанного М. К. Ганди и способствовавшего достижению Индией политической независимости и утверждению её культурной самобытности в процессе модернизации. М. К. Ганди отстаивал возможность развития общества без индустриализации и роста потребления, на основе уважения к труду, самоорганизации, самодисциплины и самообразования (там же: 487-488).
} 
Тувинская народная музыка может рассматриваться как характерный пример пространственного развития одного из элементов этнической культуры в современном мире. Как представляется, народная музыка получила приоритетное развитие по сравнению с другими элементами тувинской этнической культуры в результате действия нескольких факторов. Музыкальность является характерной чертой носителей тувинской этнической культуры (Сузукей, 2006: 50-51; Кыргыс, 2002: 14), что само по себе выделяет народную музыку в ряду других элементов этнической культуры. Помимо этого, тувинская народная музыка обладает большим своеобразием звучания, которое выделяет её среди других музыкальных этнических феноменов. И, кроме того, приоритетность пространственного развития музыки можно объяснить свойствами музыки как таковой, которая является значимым каналом коммуникации, не только переносящим информацию, но и обеспечивающим важную для человека передачу эмоций и чувств (Hsu Shen-Mou, 2017: Электр. ресурс).

\section{Основные вехи современного пространственного развития тувинской народной музыки}

Проявлением значимости музыки как части этнической культуры в целом можно считать возникновение в 1980-х гг. феномена world music, которую принято рассматривать как маркетинговую категорию для музыкальных жанров, существующих за пределами европейско-американской популярной музыки и записываемых в основном в странах третьего мира (Ventsel, 2014: 189). Данная музыкальная категория обычно применяется к области, ранее называемой «этнической музыкой», и обсуждается в контексте соотношения музыки и этничности, музыки и пространства (Guilbault, 1997: $32,41)$.

Тувинская народная музыка развивается в рамках world music с конца XX в. Однако начало процесса пространственного развития тувинского музыкального фольклора следует отнести к более раннему времени. Можно в общих чертах выделить два больших периода в его развитии. Первый период с начала XX в. и до 1980-х гг. - связан с распространением тувинской музыки сначала в пределах Российской империей, а затем СССР и стран социалистического лагеря. Второй этап связан с выходом тувинской народной музыки на глобальный уровень. Он начался с конца 1980-х гг. и продолжается до настоящего времени. Эти периоды объединены одним процессом - устойчивым воспроизводством народной музыкальной традиции в форме бытового музицирования на территории Тувы (Сузукей, 2006: 133-134).

Каждый из двух этих периодов можно разделить на два этапа. Так, для первого периода граница первого этапа соответствует 1960-м годам, когда в контексте изменения тенденций национальной политики СССР произошел рост интереса к фольклору. В течение первого этапа, до революции, А. В. Анохиным были сделаны первые фонографические записи тувинской народной музыки. Затем записи производились в 1927 г. Е.В. Гиппиусом и З.В.Эвальд в Ленинградской области (Аксенов, 1964: 14; Кыргыс, 2002: 14). А в 1934 г. по заказу Тувинской Народной Республики Московской фабрикой грамзаписи было выпущено семь граммофонных пластинок со звукозаписями тувинского музыкального фольклора (Аксенов, 1964: 3, 14).

В 1940-е - 1950-е гг., наряду с устойчивым бытовым музицированием, музыкальный фольклор воспроизводился самодеятельными коллективами на базе клубов. (Сузукей, 2006: 128-130). С 1948 г. в Туве существовал Областной дом народного творчества (переименованный затем в Республиканский научно-методический центр народного творчества и культурно-просветительской работы), который работал с самодеятельными коллективами и клубами. В рамках его работы регулярно проводились областные смотры художественной самодеятельности, которые способствовали накоплению опыта работы с народными исполнителями и выявлению талантливой молодежи (Кыргыс, 2002: 130; Сузукей, 2006: 130-131). Здесь был открыт талант мастера горлового пения Максима Дакпая (Кыргыс, 2002: 130). В 1956 г. Областным домом народного творчества был издан сборник песен «Ырлар» М. Мунзука и Ю. Кюнзегеша, ставший значимым событием для сохранения тувинской народной музыки (Аксенов, 1964: 14).

Вехой второго этапа стала вышедшая в 1964 г. монография А. Н. Аксенова «Тувинская народная музыка», которая отразила заинтересованность научного сообщества в сохранении и воспроизводстве тувинского музыкального фольклора (Аксенов, 1964). С 1960-х гг. на основе самодеятельных коллективов почти во всех районах начали создаваться фольклорные ансамбли. В результате широкой трансляции по республиканскому радио и телевидению получили известность самодеятельные артисты 
(Сузукей, 2006: 132-133). В 1970-е гг. на студии «Мелодия» был записан и несколько раз переиздавался альбом «Мелодии Тувы» (Абилдснес, 2017: Электр. ресурс). В 1975 г. сотрудниками сектора фольклора Тувинского научно-исследовательского института языка, литературы и истории был организован слет народных певцов и музыкантов (Сузукей, 2006: 136). В 1981 г. состоялся Первый республиканский фестиваль «Хоомей». В 1980-е гг. появились самобытные фольклорные коллективы (Сузукей, 2006: 134), которые в первой половине 1980-х гг. записали несколько альбомов на студии «Мелодия» (Абилдснес, 2017: Электр. ресурс).

В течение первого периода народная музыка Тувы вышла за пределы своего автохтонного региона: участники художественной самодеятельности принимали участие во всесоюзных и всероссийских смотрах и фестивалях в Москве, Новосибирске, Улан-Удэ. Исполнитель горлового пения Максим Дакпай был удостоен Золотой медали VI Всемирного фестиваля молодежи в 1957 г. в Москве. А в 1974 г. в Будапеште на Международном конкурсе обладателем гран-при «Золотого павлина» стал Сергей Куулар (Сузукей, 2006: 131). Вместе с инструментальным ансамблем «Хемчик» он также участвовал в XI Всемирном фестивале молодежи и студентов на Кубе (Кыргыс, 2002: 130). Но поскольку глобальные коммуникативные процессы в данный период ещё не получили соответствующего масштаба развития, пространственное распространение тувинской народной музыки фактически было ограничено рамками советского государства.

Второй период с конца 1980-х гг. можно охарактеризовать как наиболее интенсивный процесс пространственного развития тувинской музыки. Активизация интереса к музыкальному фольклору в этот период произошла как в самой Туве, так и за рубежом. Значимым событием в русле данной тенденции стало получение в 2017 г. И. Кошкендеем музыкальной премии Латиноамериканской академии искусства и науки звукозаписи - латинской Грэмми 1 . Подобный рост внимания к этнической культуре в целом был связан с процессами политического, социального и экономического развития как внутри, так и за пределами СССР. Характерно, что в этот же период произошло возникновение и самого феномена world music, среди его причин выделяется консолидация глобальной медиа системы и перестройка мирового экономического порядка на основе более гибкой международной системы (Connell, Gibson, 2004: 351).

В течение этого периода тувинские исполнители народной музыки начали гастролировать за рубежом и записывать в сотрудничестве с мировыми звукозаписывающими компаниями альбомы. Как отмечает Т. Левин, для тувинской музыки в период 1980-1990-х гг. была характерна так называемая «экспортная», ориентированная на зарубежную аудиторию направленность. С 1990-го г. диски записывались в западноевропейских, американских и московских студиях и не продавались в самой Туве (Левин, 2012: 76).

На начальном этапе второго периода важную роль в пространственном развитии тувинской народной музыки сыграли представители научного сообщества: как российского, так и зарубежного. В рамках работы советско-американской научной этнографической экспедиции 1987-1988 гг. были произведены собирание и запись тувинского музыкального фольклора. Эти материалы были затем (в 1990 г.) изданы некоммерческой звукозаписывающей студией Smithsonian Folkways Recordings в виде альбома Tuva: Voices from the Center of Asia (Beahrs, 2017: Электр. ресурс). В 1989 г., в Кызыле под руководством музыковеда 3. К. Кыргыс был создан ансамбль «Тыва» (Сузукей, 2006: 134). Особенностью этого ансамбля было стремление передать на концертной площадке музыкальный тувинский фольклор близко к аутентичному звучанию (Шапошников, 2017: Электр. ресурс). В конце 1980-х - начале 1990-х гг. ансамбль «Тыва» выезжал на зарубежные гастроли, были записаны два альбома, что послужило началом к участию тувинских музыкантов в коммерческих проектах (Beahrs, 2017: Электр. ресурс).

Дальнейшее пространственное развитие тувинской народной музыки в глобальном масштабе было связано сучастием тувинских музыкантов в коммерческих проектах и с изменением формата исполнения. В этот период на основе опыта ансамбля «Тыва» появились коллективы, более приспособленные к освоению глобального музыкального пространства (Шапошников, 2017: Электр. ресурс). Образцом нового формата для тувинской народной музыки и родоначальником новой системы музыкальных правил и эталоном для воспроизведения тувинского фольклора для более молодых фольклорных групп Тувы стал коллектив «Хун-Хурту» (Карелина, 2009: 457-458, 461), одним из основателей которого является входивший в состав ансамбля «Тыва» К. К. Ховалыг (Сузукей, 2006: 134).

${ }^{1}$ Первая «Grammy» в истории Тувы (2018) [Электронный ресурс] // ИА «Тува-Онлайн», 7 марта. URL: https://www.tuvaonline. ru/2018/03/07/pervaya-grammy-v-istorii-tuvy.html (дата обращения: 10.06.2019). 


\section{Родовые потребности человека как фактор современного пространственного развития этнокультуры}

Итак, в 1990-е гг. тувинский музыкальный фольклор стал участником глобальных процессов развития мировой музыкальной культуры. Подобное новое состояние тувинской народной музыки было связано с вхождением её в состав world music, которая рассматривается, прежде всего, как коммерческий феномен (Connell, Gibson, 2004: 342), маркетинговая категория. Однако коммерческий интерес, проявляемый западными компаниями к локальной, этнической музыке может пониматься не только с точки зрения коммерциализации народной музыки и её приближения к стандартам западной культуры, но и как отражение определенных потребностей слушателей, их заинтересованности в связанных с этнической культурой артефактах. В данном контексте развитие этнической музыки в глобальном масштабе можно рассматривать как обусловленное потребностями слушателей. Как, отмечается, world music отражает потребности Запада в новых звуках, источниках творчества и аутентичности (подлинности) (там же: 344). Слушатели world music являются представителями современного общества, подверженного процессам урбанизации, стандартизации. Актуальность поиска аутентичности для них основана на том, что реальность современного общества представляет собой в значительной мере псевдобытие (Бодрийяр, 2006: 164), и собственный мир слушателей поэтому воспринимается ими как эфемерный, искусственный, испорченный (Taylor, 1997: 26).

Слушатели world music ищут в ней альтернативу доминирующей коммерческой поп музыке, которая для них не обладает достаточной аутентичностью (подлинностью) и экзотикой (Ventsel, 2014: 190, 200). Аутентичность является важной составляющей world music. Выделяются три аспекта проблемы аутентичности world music. Во-первых, аутентичность понимается как отстраненность незападных артистов от капиталистического музыкального бизнеса; во-вторых, как источник эмоций, отсутствующих в западной музыке; в-третьих: как отсылка к неизменному, зафиксированному во времени прошлому, отдаленным, экзотическим, не тронутым рынком местам, связанным с ощущением устойчивости и укорененности (Connell, Gibson, 2004: 344-345, 352). Причем world music рассматривается как источник двух типов эмоций: радости и глубокой одухотворенности (Taylor, 1997: 23-25). Первый тип может рассматриваться как ощущение единения и солидарности, не свойственных западному индивидуалистическому мироощущению. А второй - как попытка единения через музыку с мирозданием, космосом, которое также перестало быть свойственно западной музыкальной традиции, начиная с XVII в. (Ганжа, 2017: 66).

Подобное понимание аутентичности world music заставляет обратиться к особенностям этнической культуры как потенциального источника данной аутентичности. Поскольку слушатели world music являются в основном представителями этнических культур, не связанных с культурами - источниками world music, то, очевидно, что общая для них необходимость аутентичности характеризует потребности слушателей world music как обладающие определенной универсальностью.

В структуре этнической культуры принято выделять два уровня: этническую специфику и культурные универсалии. Проблема культурных универсалий, объединяющих различные культуры, неоднократно затрагивалась как в отечественной, так и в зарубежной литературе. При этом указывалось на близость понятия культурных универсалий к понятию ценностей. Так, А. И. Першиц выделяет в любой культуре два слоя культурных ценностей. Первый, глубинный, отражает единство и общность культуры всех народов. Этот слой слабее этнически окрашен. Второй слой - связан с локальными культурными ценностями и более ярко окрашен этнически (Першиц, 1982: 11-12). Выделяя шесть важнейших общечеловеческих проблем, Ф. Клакхон и Ф. Штродтбек также связывали их содержание с ценностями (Kluckhohn, Strodtbeck, 1961: 4, 10).

Натуралистический подход к ценностям позволяет рассматривать их как выражение человеческих потребностей (Сурина, 1999: 7). Поэтому уровень универсалий, очевидно, отражает определенные потребности, общие для всего человечества. Среди них можно выделить две группы. Первая группа элементарные органические (биологические, физиологические) потребности, которые характерны не только для человека, но и для других живых существ. Вторая группа - потребности социальные, родовые, присущие только человеку. Поскольку ценности принято рассматривать как продукт развития и функционирования общества (Дробницкий, 1967: 312, 325, 329; Kluckhohn, 1962: 398), то они, очевидно, отражают в большей степени родовые потребности человека. Так, у Шварца и Билски восемь мотивационных областей, с помощью которых классифицируются ценности, только в одном случае напрямую связаны с физиологическими потребностями, а остальные области прямо или косвенно имеют отношению к функционированию социальной сферы (Schwarz, Bilsky, 1987: 550-553). 
Характеризуя ценностное содержание культурных универсалий, необходимо выделить ряд особенностей родовых потребностей человека. Они выражают значимость коллективного образа жизни (Момджян, 2015: 4), и долговременного, волевого способа ориентации деятельности (Узнадзе, 2001: 269-270, 272-273), а также отражают особенности потребностей роста, с которыми генетически связаны. Основой последних является необходимый для человека уже указанный долговременный способ ориентации во времени и пространстве и обеспечение его взаимодействия с как можно большим количеством сред обитания (Симонов, 1987: 48-49, 36-37, 39).

Подобная соотнесенность культурных универсалий с родовыми потребностями человека обоснована и спецификой самого традиционного общества, в рамках которого сформировалась этническая культура. Для данного общества характерен коллективизм, ключевая роль традиции, с помощью которой осуществлялась долговременная ориентация деятельности, а также постоянное взаимодействие индивида не только с социальной, но и природной средой.

Говоря в этой связи о факторах пространственного развития тувинской народной музыки в формате world music, важно подчеркнуть наличие универсалий этнической культуры, которые соотносятся с родовыми потребностями индивида. Подобное соотнесение оказывается значимым для индивида в силу того, что в современном обществе в результате роста дифференциации, специализации и технической опосредованности бытия человека для него характерно сокращение взаимодействия с естественной средой обитания. Помимо этого, в условиях распространения стандартов избыточного и не связанного с естественными потребностями потребления, рациональности на основе неустойчивых образцов («трендов»), а также - так называемой «проектной логики» развития, ориентированной на краткосрочность планирования и быстроту отдачи (Иванов, $2011: 10,13,25)$ сокращаются масштабы координат, в которых происходит ориентация деятельности индивида. Поэтому выявленные здесь особенности родовых потребностей человека оказываются значимыми на данный момент.

Однако в рамках этнической культуры её этническая специфика и культурные универсалии представляет собой единое целое. Поэтому актуальным представляется вопрос о том, какую роль играет этническая специфика культуры в процессе соотнесения с родовыми потребностями индивида.

\section{Коммуникация как механизм соотнесения этнической культуры с потребностями индивида}

Как уже было отмечено, с переходом из традиционного общества к современному, этническая культура в настоящее время испытывает существенные изменения. Они затрагивают её функционирование в качестве знаковой системы. При использовании знака не по назначению возникает нестандартный контекст из-за соотнесения знака с объектами, находящимися за пределами данной знаковой системы (Байбурин, 1995: 89-90). Поэтому для артефактов этнической культуры в современном мире характерно появление новых контекстов употребления.

Для понимания происходящих с элементами этнической культуры изменений в современном мире значимыми представляются идеи У. Эко и Ю. М. Лотмана. Согласно У. Эко, у предметов существуют не только утилитарные, но и символические значения. Подобные символические значения сообщают о возможностях пользования предмета, выходящих за рамки его узкого назначения (Эко, 2006: 273-274). Поэтому новый контекст бытования означает появление у этнической культуры новых референций.

Содержание подобных референций может быть выявлено при помощи рассмотрения элементов этнической культуры как «периферийных семиотических образований», которые понимаются Ю. М. Лотманом в качестве наличия в культуре определенного запаса текстов с утраченными кодами. Одним из их свойств является способность к реконструкции всей системы, к которой они принадлежали, но на основе нового языка, а не воссоздания старого (Лотман, 1992: 18).

Таким образом, в качестве одного из моментов функционирования элементов этнической культуры в условиях современного общества можно рассматривать появление у неё новых символических значений, основанных на формировании нового, обобщенного кода, в соответствии с которым этническая специфика культуры превращается в означаемое. Объектом, с которым начинает соотноситься подобное означаемое, становится та система, к которой этническая культура принадлежала традиционное общество во всей совокупности связанной с ним специфики общественных отношений, отличающих его от общества современного. Соответственно, в состав подобной новой референции входят связанные с этнической культурой универсалии, по происхождению связанные с традиционным обществом и обобщенно отражающие его специфику. 
Так, формируется новый семиотический код, посредством которого этническая культура соотносит индивида с содержанием культурных универсалий. Владение подобным «кодом», как представляется, формируется в период первичной социализации, когда ребенок впервые сталкивается с этнической культурой своего и других народов и когда у него формируются родовые потребности. На основе содержательного сходства данных потребностей и ценностей культурных универсалий у ребенка складывается общая область означаемых, которая соотносится с этнической культурной спецификой как означающим.

И чем более аутентичным и экзотичным по своей форме является подобное означаемое, тем легче для индивида в дальнейшем провести соотнесение и тем активнее происходит пространственное развитие этнической культуры. Как представляется, тувинская народная музыка, функционирующая в формате world music, позволяет продемонстрировать значимость аутентичности и экзотичности этнической культуры как означаемого для процесса её пространственного развития. Особенностью тувинской народной музыки в данном контексте является то, что свойственный ей так называемый «этнический код» успешно выполняет функцию подобного соотнесения.

\section{Аутентичность и неотрадиционализм тувинской народной музыки}

Анализ развития народной музыки в рамках world music сопряжен с обсуждением проблемы аутентичности, подлинности данного музыкального явления, сохранением баланса между аутентичностью и гибридизацией с доминирующей культурой (Ventsel, 2014: 191-192). Для тувинской народной музыки на данном этапе её развития была выработана новая эстетика, позволяющая, с одной стороны, функционировать в формате world music, а с другой стороны, сохранять аутентичность, специфику тувинского музыкального фольклора.

Как уже отмечалось, с возникновением «Хун-Хурту» традиционный музыкальный материал был переосмыслен и модифицирован (Карелина, 2009: 457-458, 461). При этом «Хун-Хурту» создали новую, можно сказать, неотрадиционную эстетическую модель исполнения традиционных тувинских песен (о феномене социокультурного неотрадиционализма см.: Мадюкова, Попков, 2011), которая, позволяла подчеркнуть древность исполняемого материала и создать с помощью обновленного звучания атмосферу, погружающую слушателя в природные, характерные для Тувы естественные ритмы (Beahrs, 2017: Электр. ресурс). На наш взгляд, у созданной «Хун-Хурту» неотрадиционной музыкальной эстетики можно выделить три источника. Во-первых, сам тувинский музыкальный фольклор и живая музыкальная традиция. Во-вторых, влияние, которое испытали участники коллектива со стороны западной музыки. Здесь следует выделить роль отдельных исполнителей: так, А. Кувезин (входивший в первые годы в состав коллектива, впоследствии организовал свою группу «Ят-Ха») отмечал влияние на его творчество Led Zeppelin, a С. Бапа - влияние американского джаз-фьюжн коллектива Weather Report и Фрэнка Заппы (Frank Zappa). Кроме того, важно характерное для world music включение в нее технического потенциала западной культурной традиции. И, в третьих, ещё одним источником стало влияние научного сообщества, которое происходило в форме участия американского этномузыковеда Т. Левина в становление неотрадиционной эстетики «Хун-Хурту». В период записи первых трех альбомов Т. Левин являлся исполнительным продюсером группы (Beahrs, 2017: Электр. pесурс). Таким образом, формирование неотрадиции в исполнении тувинской народной музыки означало не только характерный для world music синтез традиционной и массовой западной культуры, но и влияние научного знания.

Вместе с тем, неотрадиционная эстетика развивает уже присущие тувинской народной музыке традиционность и этническое своеобразие, которые сами по себе являются значительными. Так, высокая степень аутентичности традиционной народной культуры Тувы является важной особенностью данного региона, которая была обусловлена поздним вступлением Тувы в состав СССР (Сузукей, 2006: 175). Советский период также не стал для Тувы периодом слома её традиционности, поскольку, с одной стороны, традиция в Туве характеризуется устойчивостью и фундаментальностью и музыкальные традиции воспроизводились в течение всего советского периода на бытовом уровне (там же: 132). И, кроме того, с тувинской традиционностью боролись и противопоставляли ее новой советской культуре в 1930-1950 гг., но затем стало очевидно, что советская культура также основана на соблюдении ряда базовых традиций (Ламажаа, 2011).

Природа этнического своеобразия и выразительности тувинской народной музыки связана с особенностями звуковой организации тувинского музыкального фольклора, которые резко контрастиру- 
ют с европейской музыкальной традицией. Так, для тувинцев музыкой является не только тот материал, который четко организован по высоте, темпу и ритму, как это принято в европейской музыкальной культуре, но и звуки, богатые по тембру. Тембр является первоосновой музыкального мышления тувинцев и его яркой особенностью (Сузукей, 2006: 33-34, 56-59).

Ориентация на тембр означает, что, в отличие от европейской музыки, в которой в звуке все обертоны сливаются в один, в тувинской народной музыке в одном звуке раскрывается целый акустический мир, созданный распылением обертонов (Левин, 2012: 82). Причем обертоны в тувинской инструментальной музыке извлекаются там же, где и бурдон (Сузукей, 2006: 188; Сузукей, 2010: 88, 91-92, 95). Специфика восприятия подобной музыки проявляется в том, что во время прослушивания горлового пения за счет выделения обертонов на фоне основного тона («тембровый парадокс») у слушателя появляется чувство, что он способен ощущать необычные явления, например, присутствие духов, иными словами, осуществляется переход к иному восприятию мира (Левин, 2012: 90-91).

Кроме того, тембровое восприятие звука является идеальным акустическим зеркалом природы. Акустические картины природы погружают исполнителя и слушателя в атмосферу природного ландшафта, создавая ощущение присутствия (Левин, 2012: 93, 143). Для тувинского музыкального фольклора обращение к естественной среде обитания является содержательной доминантой (Сузукей, 2006: 30, 27, 36; Карелина, 2009: 24). Не только содержание, но и форма тувинской музыки определяются звуковым ландшафтом региона. (Levin, Edgerton, 1999: 80). Свойственная тувинской музыке объемность, многократность, пространственность звукового потока позволяет создать голографический, а не фотографический образ природы. (Сузукей, 2006: 30, 33).

Тувинская народная музыка в формате world music полностью соответствует запросу современного слушателя на аутентичность. Последняя выражена здесь в особенностях звучания - ориентированности на тембр, традиционности и наполненности легко ощутимыми образами естественной среды обитания человека. Помимо этого, аутентичность тувинской народной музыки усиливается тем психофизическим эффектом «тембрового парадокса», который она оказывает на слушателя. В данном контексте тувинская народная музыка ассоциируется именно с глубокой одухотворенностью и сакральностью (Taylor, 1997: 25).

Донесение подобной аутентичности до современного слушателя стало возможным благодаря выработке так называемого нового «кода» прочтения тувинской народной музыки, реализованного в новой эстетике, синтезированной на основе живой исполнительской традиции, научной рефлексии и профессионального исполнительского искусства. Особенностью данного кода стало не только сохранение, но и усиление свойственного тувинской музыке своеобразия.

\section{Заключение}

Для пространственного развития этнической культуры в современном мире характерно, с одной стороны, обеспечение ее доступными коммуникативными каналами для обмена информацией с глобальным пространством, а с другой стороны, процесс её коммерциализации. Коммерциализация может рассматриваться как поиск ресурсов, необходимых для удовлетворения запросов потребителей в частности, представителей западной глобальной культуры. Обращение к незападным, локальным источникам свидетельствует о том, что в данном случае речь идет о потребностях, которые индивид не может реализовать в рамках западной культуры.

С одной стороны, содержание подобных потребностей представителя современной западной культуры можно рассматривать как характерное для данной культуры проявление стремления $\mathrm{k}$ новизне, обновлению впечатлений (Парыгин, 1974: 95-97). Но с другой стороны, конкретизация содержания данных потребностей на примере понятия «аутентичности» world music, показывает, что подобные потребности отражают более глубокую, чем требование новизны, необходимость - необходимость более укорененного, последовательного, духовного способа существования. В подобном контексте, локальное - этническая культура - может рассматриваться как альтернатива западной культуре с точки зрения доминирующих в ней ценностных ориентаций, поскольку последние отражают приоритетность реализации потребностей в соответствии с иерархией ценностей, характерной для данного типа культуры.

В процессе пространственного развития элементы этнической культуры выступают как закодированное сообщение. Чтобы подобное сообщение было понято адресатом, этническая специ- 
фика культуры должна быть сохранена и в то же время адаптирована к тезаурусу представителя современного западного общества. Соблюдение подобного баланса демонстрирует неотрадиционная эстетика тувинской музыки, особенность которой составляет использование этнической культуры как терминальной ценности, а западной - как инструментальной для выражения этнической специфики тувинской культуры.

Содержание подобного сообщения составляют те ценности, которые в современной западной культуре находятся на периферии системы ценностных ориентаций и не позволяют в должной степени реализоваться связанным с данными ценностями родовым потребностям индивида. Данные потребности представляют собой один из значимых факторов пространственного развития этнической культуры в современном мире. В ходе данной работы среди особенностей этих потребностей были выделены: необходимость в коллективном способе жизни, генетически связанная с познавательными потребностями нужда индивида в долговременной перспективе ориентации деятельности, а также во взаимодействии с естественной, природной средой обитания.

Подводя итоги, можно сказать, что пространственное развитие этнической культуры является необходимой частью процесса формирования нового типа культуры, основой которого является сбалансированная система ценностей, отводящая значимое место не только индивидуалистическим ценностям личного самосохранения, но в необходимой мере отражающая ценностные ориентации, связанные с родовой сущностью человека и обеспечивающие его самосохранение как вида.

\section{СПИСОК ЛИТЕРАТУРЫ}

Абилдснес, М. (2017) Тувинская музыка и ее дискография (основные имена, названия, проблемы описания) [Электронный ресурс] // Новые исследования Тувы. № 2. URL: https://nit.tuva.asia/nit/article/ view/706 (дата обращения: 05.03.2019). DOI: DOI: 10.25178/nit.2017.2.6

Аксенов, А. Н. (1964) Тувинская народная музыка. М. : Музыка. 238 с.

Арутюнов, С. А. (1979) Этнографическая наука и изучение культурной динамики // Исследования по общей этнографии / отв. ред. Ю. В. Бромлей. М.: Наука. 277 с. С. 24-60.

Арутюнов, С. А. (1989) Народы и культуры: развитие и взаимодействие. М. : Наука. 247 с.

Байбурин, А. К. (1995) Семиотический статус вещей и мифология // Кунсткамера. Избранные статьи / сост. А. К. Байбурин, Н. М. Гиренко, К. В. Чистов. СПб.: Европейский дом. 414 с. С. 80-96.

Беккин, Р. И. (2010) Исламская экономическая модель и современность. М. : Изд. дом Марджани. 352 c.

Беккин, Р. И. (2012) Исламская экономика: универсальная теория развития или одна из моделей третьего пути? // Восток. № 5. С. 99-112.

Бергер, П. Л. (2004) Культурная динамика глобализации // Многоликая глобализация / под ред. П. Бергера и С. Хантингтона. М. : Аспект Пресс. 379 с. С. 8-27.

Бодрийяр, Ж. (2006) Общество потребления. Его мифы и структуры. М. : Республика ; Культурная революция. 269 с.

Ганжа, А. (2017) Культура как препятствие: размузыкаливание мира в гибридных дискурсах музыкального воздействия // Социологическое обозрение. Т. 16. № 1. С. 50-82. DOI: 10.17323/1728-192X2017-1-50-82

Дробницкий, О. Г. (1967) Мир оживших предметов. Проблема ценности и марксистская философия. М. : Изд-во политической литературы. 350 с.

Зарубина, Н. Н. (1998) Социокультурные факторы хозяйственного развития: М. Вебер и современные теории модернизации. СПб. : РХГИ. 288 с.

Иванов, Д. В. (2011) Глэм-капитализм: общество потребления в XXI веке // Журнал социологии и социальной антропологии. T. XIV. № 5 (58). С. 9-29.

Ильин, Е. П. (2002) Мотивация и мотивы. СПб. : Питер. 512 с.

Карелина, Е. К. (2009) История тувинской музыки от падения династии Цин и до наших дней: исследование. М. : Композитор. 552 с.

Культура и пространство: историко-культурные бренды и образы территории, регионов и мест (2012) / отв. ред. В. К. Малькова, В. А. Тишков. Ростов на Дону : Издательство ЮНЦ РАН. 312 с. 
Кыргыс, 3. К. (2002) Тувинское горловое пение: Этномузыковедческое исследование. Новосибирск : Наука. 236 с.

Ламажаа, Ч. К. (2011) Тува между прошлым и будущим. 2-е изд. СПб. : Алетейя. 368 с.

Левин, Т. (2012), при участии В. Ю. Сузукей. Музыка новых номадов. Горловое пение в Туве и за её пределами. М. : Издательский дом «Классика-XXI». 336 с.

Лотман, Ю. М. (1992) О семиосфере // Лотман Ю. М. Избранные статьи : в 3 т. Таллин : Александра. T. I. 479 c. C. $11-25$.

Любарт, М. К. (2013) Праздник «Фес-ноз» как явление в современной культуре бретонцев // Очерки о европейской идентичности и многокультурности / отв. ред. М. Ю. Мартынова. М. : ИЭА РАН. 480 с. C. 321-358.

Мадюкова, С. А., Попков, Ю. В. (2011) Феномен социокультурного неотрадиционализма. СПб. : Алетейя. 132 с.

Момджян, К. Х. (2015) Универсальные потребности и родовая сущность человека // Вопросы философии. № 2. С. 3-13.

Монгуш, М., Зайцева, А., Бакшеев, Е. (2014) «Этническая культура»: содержание и составляющие понятия [Электронный ресурс] // Культурологический журнал. № 2. URL: http://www.intelros.ru/readroom/ kulturologicheskiy-zhurnal/kul2-2014/25090-etnicheskaya-kultura-soderzhanie-i-sostavlyayuschie-ponyatiya.html (дата обращения: 26.03.2019)

Парыгин, Б. Д. (1974) Научно-техническая революция и динамика социальных потребностей // Проблемы формирования социогенных потребностей. Материалы I Всесоюзной конференции (4-6 ноября 1974, Тбилиси) / отв. ред. Ш. Н. Чхартишвили, Н. И. Сарджвеладзе. Тбилиси : Институт психологии. 307 c. С. $95-98$.

Першиц, А. И. (1982) Проблема аксиологических сопоставлений в культуре // Советская этнография. № 3. С. 8-12.

Попков, Ю. В. (2000) Интернационализация в традиционном и современном обществах. Новосибирск : Изд-во ИДМИ. 200 с.

Попков, Ю.В. (2012) Этносоциальные процессы и этнонациональная политика // Вестник Российской академии наук. T. 82. № 12. C. 1067-1074. DOI: 10.1134/S1019331612060093

Симонов, П. В. (1987) Мотивированный мозг. Высшая нервная деятельность и естественнонаучные основы общей психологии. М. : Наука. 270 с.

Сравнительное изучение цивилизаций (1998): хрестоматия, учебное пособие для студентов вузов / ред. Б. С. Ерасов. М. : Аспект-пресс. 556 с.

Старостин, Б. С. (1984) Освободившиеся страны: общество и личность. Критический анализ немарксистских концепций. М. : Мысль. 282 с.

Сузукей, В. Ю. (2006) Конфигурация развития музыкальной культуры Тувы: динамика аксиологического аспекта. Кемерово : Кемеровский гос. ун-т культуры и искусств. 205 с.

Сузукей, В. Ю. (2010) О специфике музыкального языка инструментального искусства тувинцев // Урало-алтайские исследования. № 2 (3). С. 88-98.

Сурина, И. А. (1999) Ценности. Ценностные ориентации. Ценностное пространство. Вопросы теории и методологии. М. : Институт молодежи. 183 с.

Узнадзе, Д. Н. (2001) Психология установки. СПб.: Питер. 416 с.

Шапошников, М. В. (2017) Тувинская музыка и World Music [Электронный ресурс] // Новые исследования Тувы. № 2. URL: https://nit.tuva.asia/nit/article/view/712 (дата обращения: 05.03.2019). DOI: 10.25178/nit.2017.2.5

Эко, У. (2006) Отсутствующая структура. Введение в семиологию. СПб.: Симпозиум. 544 с.

Hsu Shen-Mou (2017) Social and cognitive functions of music based on the exampleof Tuvan throat singing [Электронный ресурс] // Новые исследования Тувы. № 2. С. 177-185. URL: https://nit.tuva.asia/nit/ article/view/719 (дата обращения: 05.03.2019). DOI: 10.25178/nit.2017.2.8

Beahrs, R. O. (2017) Nomads in the Global Soundscape: Negotiating Aesthetics in PostSoviet Tuva's Traditional Music Productions [Электронный ресурс] // Новые исследования Тувы. № 2. URL: https://nit. tuva.asia/nit/article/view/716 (дата обращения: 05.03.2019). DOI: 10.25178/nit.2017.2.3

Connell, J., Gibson, Ch. (2004) World music: deterritorializing place and identity // Progress in Human Geography. No. 28 (3). P. 342-361. 
Guilbault, J. (1993) On Redefining the "Local" Through World Music // The World of Music. Vol. 35. No. 2. P. 33-47.

Guilbault, J. (1997) Interpreting World Music: A Challenge in Theory and Practice // Popular Music. Vol. 16. No. 1. P. 31-44.

Kluckhohn, C. (1962) Values and Values-Orientations in the Theory of Action: An Exploration in Definition and Classification // Toward General Theory of Action ed. T. Parsons and E. A. Shils. Harvard University Press. 506 p. P. 388-434.

Kluckhohn, F. R., Strodtbeck, F. L. (1961) Variations in Value Orientations. Evanston, Illinois : Row, Peterson. $451 \mathrm{p}$.

Levin, T. C., Edgerton, M. E. (1999) The Throat-Singers of Tuva // Scientific American. No. 281. P. 80-87.

Robertson, R. (1995) Glocalization: Time-Space Homogeneity-Heterogeneity // Global Modernities. Ed. by M. Featherstone et al. London: Sage. 292 p. P. 25-44.

Schwarz, Sh., Bilsky, W. (1987) Toward A Universal Psychological Structure of Human Values // Journal of Personality and Social Psychology. Vol. 53. No. 3. P. 550-562.

Taylor, T. D. (1997) Global Pop: world music, world markets. New York : Routledge. 258 p.

Ventsel, A. (2014) World music routes: the modification of the Sakha musical tradition // InterDisciplines. No. 1. P. $189-206$.

Дата поступления: 03.06.2019 2.

\section{REFERENCES}

Abildsnes, M. (2017) Tuvinskaia muzyka i ee diskografiia (osnovnye imena, nazvaniia, problemy opisaniia) [Tuvan music and its discography (principal names, titles, issues of description)]. The New Research of Tuva, no. 2, pp. 142-164. 142-164. [online] Available at: https://nit.tuva.asia/nit/article/view/706 (access date: 05.03.2019). (In Russ.). DOI: 10.25178/nit.2017.2.6 (In Russ.).

Aksenov, A. N. (1964) Tuvinskaia narodnaia muzyka [Tuvan folk music]. Moscow, Muzyka. 238 p. (In Russ).

Arutiunov, S. A. (1979) Etnograficheskaia nauka i izuchenie kul'turnoi dinamiki [Ethnology and the study of cultural dynamics]. In: Issledovaniia po obshchei etnografii [Research in general ethnography]. Ed. by Yu. V. Bromlei. Moscow, Nauka. 277 p. Pp. 24-60. (In Russ).

Arutiunov, S.A. (1989) Narody i kul'tury: razvitie i vzaimodeistvie [Peoples and cultures: their development and interaction]. Moscow, Nauka. 247 p. (In Russ).

Baiburin, A. K. (1995) Semioticheskii status veshchei i mifologiia [Semiotic Status of Things and Mythology]. In: Kunstkamera. Izbrannye stat'i [Peter the Great Museum of Anthropology and Ethnography: Selected articles]. Ed. by. A. K. Baiburin, N. M. Girenko and K. V. Chistov. St. Petersburg, Evropeiskii dom. 414 p. Pp. 80-96. (In Russ).

Bekkin, R. I. (2010) Islamskaia ekonomicheskaia model' i sovremennost' [The Islamic economic model and modernity]. Moscow, Mardzhani Publishing House. 352 p. (In Russ).

Bekkin, R. I. (2012) Islamskaia ekonomika: universal'naia teoriia razvitiia ili odna iz modelei tret'ego puti? [The Islamic economics: Universal theory or a model of the Third Way?]. Vostok, no. 5, pp. 99-112. (In Russ).

Berger, P. L. (2004) Kul'turnaia dinamika globalizatsii [The cultural dynamics of globalization]. In: Mnogolikaia globalizatsiia [Many globalizations: Cultural diversity in contemporary world]. Ed. by P. L. Berger and S. P. Huntington. Moscow, Aspekt Press. 379 p. Pp. 8-27. (In Russ).

Baudrillard, J. (2006) Obshchestvo potrebleniia. Ego mify i struktury [The consumer society: myths and structures]. Moscow, Respublika, Kul'turnaia revoliutsiia. 269 p. (In Russ).

Ganzha, A. (2017) Culture as obstacle: Demusicalization of the world in the hybrid discourses of the effects of music. Russian Sociological Review, vol. 16, no. 1, pp. 50-82. (In Russ). DOI: 10.17323/1728-192X-2017-150-82

Drobnitskii, O. G. (1967) Mir ozhivshikh predmetov. Problema tsennosti i marksistskaia filosofiia [The world of animated objects: The question of values in Marxist philosophy]. Moscow, Politicheskoi literatury publ. $350 \mathrm{p}$. (In Russ).

Zarubina, N. N. (1998) Sotsiokul'turnye faktory khoziaistvennogo razvitiia: M. Veber i sovremennye teorii modernizatsii. [Sociocultural factors of economic development: $M$. Weber and contemporary theories of modernization]. St. Petersburg, RKhGI. 288 p. (In Russ). 
Ivanov, D. V. (2011) Glam-Capitalism: Consumer Society in the XXI st Century. The Journal of Sociology And Social Anthropology, vol. XIV, no. 5 (58), pp. 9-29. (In Russ).

Il'in, E. P. (2002) Motivatsiia i motivy [Motivation and Motive]. St. Petersburg, Piter. 512 p. (In Russ).

Karelina, E. K. (2009) Istoriia tuvinskoi muzyki ot padeniia dinastii Tsin i do nashikh dnei: issledovanie [A history of Tuvan music from the fall of the Qing dynasty to the present day]. Moscow, Kompozitor Publ. 552 p. (In Russ).

Kul'tura i prostranstvo: istoriko-kul'turnye brendy i obrazy territorii, regionov i mest [Culture and space: Historical and cultural brands and images of territories, regions and localities] (2012). Ed. by V. K. Mal'kova and V. A. Tishkov. Rostov-on-Don, SSC RAS Publishers. 312 p. (In Russ).

Kyrgys, Z. K. (2002) Tuvinskoe gorlovoe penie: Etnomuzykovedcheskoe issledovanie [Throat singing of Tuva: an ethnomusiciligical study]. Novosibirsk, Nauka. 236 p. (In Russ).

Lamazhaa, Ch. K. (2011) Tuva mezhdu proshlym i budushchim [Tuva between Past and Future]. 2nd ed. St. Petersburg, Aleteiia. 368 p. (In Russ).

Levin, T. (2012) Muzyka novykh nomadov. Gorlovoe penie $v$ Tuve i za ee predelami [Where Rivers and Mountains Sing: Sound, Music, and Nomadism in Tuva and Beyond]. Moscow, Klassika-XXI Publ. 336 p. (In Russ).

Lotman, Yu. M. (1992) O semiosfere [On semiosphere]. In: Lotman Yu. M. Izbrannye stat'i [Selected articles] : in 3 vol. Tallin, Aleksandra. Vol. I. 479 p. Pp. 11-25. (In Russ).

Liubart, M. K. (2013) Prazdnik «Fes-noz» kak iavlenie v sovremennoi kul'ture bretontsev [The Fes-noz festival as a phenomenon of modern Breton culture]. In: Ocherki o evropeiskoi identichnosti i mnogokul'turnosti [Essays on European identity and interculturality]. Ed. by M. Yu. Martynova. Moscow, IEA RAN. 480 p. Pp. 321-358. (In Russ).

Madiukova, S. A. and Popkov, Yu. V. (2011) Fenomen sotsiokul'turnogo neotraditsionalizma [The phenomenon of sociocultural neotraditionalism]. St. Petersburg, Aleteiia. 132 p. (In Russ).

Momdzhian, K. Kh. (2015) Universal'nye potrebnosti i rodovaia sushchnost' cheloveka [Universal needs and generic human essence]. Voprosy filosofii, no. 2, pp. 3-13. (In Russ.).

Mongush, M., Zaitseva, A. and Baksheev, E. (2014) «Etnicheskaia kul'tura»: soderzhanie i sostavliaiushchie poniatiia [Ethnic culture: its content and constituent elements]. Journal of Cultural Research, no. 2. [online] Available at: http://www.intelros.ru/readroom/kulturologicheskiy-zhurnal/kul2-2014/25090-etnicheskayakultura-soderzhanie-i-sostavlyayuschie-ponyatiya.html (access date: 26.03.2019.). (In Russ).

Parygin, B. D. (1974) Nauchno-tekhnicheskaia revoliutsiia i dinamika sotsial'nykh potrebnostei. [The technological revolution and the dynamics of social needs]. In: Problemy formirovaniia sotsiogennykh potrebnostei [Problems of developing of social needs]. Proceedings of the 1st National Conference. Ed. by Sh. N Chkhartishvili and N. I. Sardzhveladze. Tbilisi, Institut psikhologii. 307 p. Pp. 95-98. (In Russ).

Pershits, A. I. (1982) Problema aksiologicheskikh sopostavlenii v kul'ture [The problem of axiological comparisons in culture]. Sovetskaia etnografiia, no. 3, pp. 3-12. (In Russ).

Popkov, Yu. V. (2000) Internatsionalizatsiia v traditsionnom i sovremennom obshchestvakh [Internationalization in traditional and contemporary societies]. Novosibirsk, IDMI Publ. 200 p. (In Russ).

Popkov, Yu. V. (2012) Etnosotsial'nye protsessy i etnonatsional'naia politika [Ethnosocial processes and ethnonational politics]. Herald of the Russian Academy of Sciences, vol. 82, no. 12, pp. 1067-1074. (In Russ). DOI: $10.1134 /$ S1019331612060093

Simonov, P. V. (1987) Motivirovannyi mozg. Vysshaia nervnaia deiatel'nost' i estestvennonauchnye osnovy obshchei psikhologii [The motivated brain. Higher nervous activity and the foundations of general psychology in natural science]. Moscow, Nauka. 270 p. (In Russ).

Sravnitel'noe izuchenie tsivilizatsii [Comparative studies of civilization] (1998) : Compilation. Study guide for students / ed. by B. S. Erasov. Moscow, Aspekt-press. 556 p. (In Russ.).

Starostin, B. S. (1984) Osvobodivshiesia strany: obshchestvo i lichnost'. Kriticheskii analiz nemarksistskikh kontseptsii [Former colonial countries: Society and personality]. Moscow, Mysl'. 282 p. (In Russ).

Suzukei, V. Yu. (2006) Konfiguratsiia razvitiia muzykal'noi kul'tury Tuvy: dinamika aksiologicheskogo aspekta [Configuration of development of Tuvan musical culture: Dynamics of the axiological aspect]. Kemerovo, Kemerovskii gos. un-t kul'tury i iskusstv. 205 p. (In Russ).

Suzukei, V. Yu. (2010) Special features of the musical language in Tyva instrumental art. Ural-Altaic Studies, no. 2 (3), pp. 88-98. (In Russ). 
Surina, I. A. (1999) Tsennosti. Tsennostnye orientatsii. Tsennostnoe prostranstvo. Voprosy teorii i metodologii [Values. Value orientations. Space of values. Theoretical and methodological issues]. Moscow, Institut molodezhi. 183 p. (In Russ).

Uznadze, D. N. (2001) Psikhologiia ustanovki [The psychology of set]. St. Petersburg, Piter. 416 p. (In Russ).

Shaposhnikov, M. V. (2017) Tuvan music and World Music. The New Research of Tuva, no. 2, pp. 122-141 [online] Available at: https://nit.tuva.asia/nit/article/view/712 (access date: 05.03.2019). DOI: 10.25178/ nit.2017.2.5 (In Russ).

Eco, U. (2006) Otsutstvuiushchaia struktura. Vvedenie v semiologiiu [The absent structure: introduction to semiotics]. St. Petersburg, Simpozium. 544 p. (In Russ).

Hsu, Shen-Mou (2017) Social and cognitive functions of music based on the example of Tuvan throat singing. The New Research of Tuva. no. 2. pp. 177-185. [online] Available at: https://nit.tuva.asia/nit/article/ view/719 (access date: 05.03.2019). DOI: 10.25178/nit.2017.2.8

Beahrs, R. O. (2017) Nomads in the Global Soundscape: Negotiating Aesthetics in PostSoviet Tuva's Traditional Music Productions. The New Research of Tuva, no. 2. pp. 59-110. [online] Available at: https://nit.tuva. asia/nit/article/view/716 (access date: 05.03.2019). DOI: 10.25178/nit.2017.2.3

Connell, J. and Gibson, Ch. (2004) World music: deterritorializing place and identity. Progress in Human Geography, no. 28 (3), pp. 342-361.

Guilbault, J. (1993) On redefining the "local" through world music. The World of Music, vol. 35, no. 2, pp. 33-47.

Guilbault, J. (1997) Interpreting world music: A challenge in theory and practice. Popular Music, vol. 16, no. 1, pp. 31-44.

Kluckhohn, C. (1962) Values and Values-Orientations in the Theory of Action: An Exploration in Definition and Classification. In: Toward General Theory of Action. Harvard University Press. 506 p. Pp. 388-434.

Kluckhohn, F. R. and Strodtbeck, F. L. (1961) Variations in Value Orientations. Evanston, Illinois, Row, Peterson. $451 \mathrm{p}$.

Levin, T. C. and Edgerton, M. E. (1999) The Throat-Singers of Tuva. Scientific American. no. 281, p. 80-87.

Robertson, R. (1995) Glocalization: Time-Space and Homogeneity-Heterogeneity. In: Global Modernities. Ed. by M. Featherstone, S. Lash and R. Robertson. London, Sage. 292 p. Pp. 25-44.

Schwarz, Sh. and Bilsky, W. (1987) Toward a Universal Psychological Structure of Human Values. Journal of Personality and Social Psychology, vol. 53, no. 3, pp. 550-562.

Taylor, T. D. (1997) Global Pop: world music, world markets. New York, Routledge. 258 p.

Ventsel, A. (2014) World music routes: the modification of the Sakha musical tradition. InterDisciplines, no. 1, pp. 189-206.

Submission date: 03.06.2019. 